
\title{
25 Research Square \\ Postpartum contraceptive use among low-income urban women: insights from Accra, Ghana
}

\section{Caesar Agula}

University of Ghana

Elizabeth G. Henry

Harvard T.H. Chan School of Public Health

Patrick Asuming

University of Ghana

Akua Obeng-Dwamena

University of Ghana

Theophilus Toprah

University of Ghana

Martin W. Agyekum

University of Ghana

Iqbal Shah

Harvard T.H. Chan School of Public Health

Ayaga A. Bawah ( $\sim$ aabawah@ug.edu.gh )

University of Ghana

\section{Research Article}

Keywords: Postpartum contraceptive use, Low-income urban women, Ghana

Posted Date: February 4th, 2022

DOl: https://doi.org/10.21203/rs.3.rs-1275079/v1

License: (c) (i) This work is licensed under a Creative Commons Attribution 4.0 International License. Read Full License 


\section{Abstract}

Background: Postpartum contraceptives use (PPC) reduces unintended pregnancies and results in better health outcomes for children and women. However, in Ghana, there is a paucity of knowledge on PPC use, particularly among women in low-income urban settings. To shed light on strategies that might enhance access to postpartum family planning services in low-income urban settings, we examined contraceptive use among postpartum women in Accra, Ghana, at one, three, six and twelve months following the birth and the methods used. The predictors of modern contraceptive use in the 12 months postpartum period were also examined.

Methods: Data are from a cross-sectional survey that was conducted in 2018 among 624 women aged 16-44 years who reported to have given birth in the past 13-31 months prior to the interview. We generated descriptive statistics to examine the prevalence of contraceptive use among postpartum women at one, three, six and twelve months after birth. We further estimated a binary logistic regression to examine the predictors of 12 months postpartum modern contraceptive use.

Results: Data indicate that $40 \%$ of postpartum women never used any contraceptive method during one year after birth and of those who used a method, $40 \%$ relied on traditional methods. Moreover, $29 \%$ of women started using a method in the immediate one-month post-birth. Results further show that postpartum modern contraceptive uptake was positively associated with higher education, having more live births and being currently in a union.

Conclusions: Findings highlight the need to improve the quality of counselling during antenatal and postnatal care visits by clients. Community outreach by health providers/promoters or similar models should be promoted in low-income population settings to educate postpartum women on modern contraceptive use. Women who plan to use traditional methods should be provided with information on consistent and correct use of these methods.

\section{Background}

The benefits associated with the use of contraceptives are enormous and transcend health to economic and social empowerment of women and households [1]. According to the World Health Organization (WHO), postpartum women have the highest unmet need for contraception [2]. Studies show that about $70 \%$ of postpartum women who desire to prevent pregnancy for the next two years are not using any contraceptive method $[2,3]$. Contraception uptake within the first 12 months of postpartum can significantly reduce unintended pregnancies, and is particularly important because women and children under-five years simultaneously achieve best health outcomes when pregnancy intervals are long [4-9]. A minimum of 24 months following live birth is recommended before next pregnancy whereas a six-month period is recommended for next pregnancy after miscarriage or abortion $[6,8]$. Women who delay the next pregnancy after birth, miscarriage or abortion have a lower risk of maternal and child mortality, low birth weight and pre-term birth [8].

Certain fertility behaviours potentially increase or reduce the risk of pregnancy during 12 months postpartum period and these include the use of contraceptives, resumption of sexual activity, breastfeeding and return of menstruation $[4,6]$. Women who exclusively breastfeed for the first 6 months after birth and are amenorrhoeic are unlikely to become pregnant within the first 6 months postpartum period [4]. However, after 6 months their risk of becoming pregnant increases with time [4]. Postpartum women who use contraceptives in addition to practicing exclusive breastfeeding without the return of menstruation have extra protection against unintended pregnancy $[6,10]$. 
In most low- and middle-income countries (LMICs), the use of contraceptives, especially modern methods after birth is generally low [5]. A systematic review of literature between 1997 and 2018 shows that the overall postpartum modern contraceptive prevalence rate (mCPR) in LMICs is about $41 \%$, with West Africa having the lowest mCPR (36\%) whereas South Asia/South East Asia have the highest rate (42\%) [5]. Likewise, in Ghana, postpartum modern contraceptive uptake is low. Studies in the country reported postpartum modern contraceptive use among women varying between $25 \%$ and $26.5 \%$ based on the health facility studied and the location of the facility $[5,11,12]$. For instance, the reported postpartum modern contraceptive use for Tema General Hospital and Tema Polyclinic, Accra in 2018 was 26.3\% whereas 26.5\% was reported for a well-baby clinic of Komfo Anokye Teaching Hospital, Kumasi in 2011 [11, 12]. Some of the factors influencing the use of modern contraceptives by women in Ghana during postpartum period include prior use of contraceptives before pregnancy, return of menstruation, resumption of sexual activity and having received maternal health services such as family planning counselling during antenatal care (ANC) [11].

Though a few postpartum contraceptive use studies have been carried out in Ghana, largely these studies are facility-based [6, 11, 12]. Moreover, Atiglo and Biney [13] who used a population-based data (Ghana Demographic and Health Survey) to assess postpartum contraceptive use among unmarried young women in Ghana did not give the context of the low-income urban population. Unlike other urban settings, urban poor women are predisposed to the effects of urbanization such as floods, congestions and other health hazards, and sometimes have inequitable access to health services $[14,15]$. To shed light on strategies that might enhance access to postpartum services and reduce unintended pregnancies in low-income settings of urban populations in Ghana, we examined the prevalence of immediate, one, three, six and twelve months postpartum contraceptive use among women who have had a live birth in Accra and the methods they used. Also, the predictors of modern contraceptive use in the 12 months postpartum period were examined. The study hypothesizes that socioeconomic attributes of women and their use of antenatal and postnatal care services affect their modern contraceptive uptake within 12 months postpartum period.

\section{Methods}

\section{Study setting}

This paper used data from a larger community representative cross-sectional study conducted in low-income urban settings of Accra, Ghana. The larger study, referred to as Willows Impact Evaluation (WIE), surveyed women living in two poor neighborhoods of Accra, Ghana. The first neighborhood include La, Teshie and Nungua communities which are located at the coastal part of Accra. The second neighborhood is inland and include La Nkwantanang-Madina, Abogba and Old Ashongman communities. All six communities share similar socioeconomic, demographic and ethnic mix attributes. Unlike the formal settings of urban cities, the study area is relatively poor and often predisposed to the effects of urbanization such as floods, pollution, congestion and outbreak of diseases $[14,15]$.

\section{Sampling}

The WIE study employed a three-level cluster sampling technique. At the first level, 200 clusters (100 each for the coastal and inland communities) were randomly sampled from equally-divided enumeration area maps of the study communities obtained from the Ghana Statistical Service (GSS). All women in their reproductive ages 1644 years within the sampled clusters were subsequently listed. A total of 5,651 households with women aged 16- 
44 years were listed from the sampled clusters. At the second level of the sampling, an average of 25 households were randomly sampled from each cluster. The inclusion criteria for the sampled household was for each to have at least one woman within the ages 16-44 years. At the third level, one eligible woman was sampled and interviewed in the case where the sampled household had more than one eligible woman. A total of 4,184 women out of 4,323 contacted consented to be part of the WIE and had completed interviews. However, this paper used data for 624 women who reported in the contraceptive calendar section of the questionnaire to have given birth in the past 13-31 months prior the interview.

\section{Data collection}

Data were collected with the use of electronic devices (tablets) which were programmed with a questionnaire using CommCare software application [16]. Data collection spanned from January to July 2018. Prior to data collection, field enumerators and supervisors were extensively trained for two weeks by an experienced research team from the University of Ghana, Ghana Health Service and Harvard T.H. Chan School of Public Health. The data collected include background characteristics and health information of women, including questions on their reproductive health such as contraceptive use, pregnancies and abortions. All interviews were conducted through a face-to-face interaction between enumerators and participating women in either English or local language.

\section{Measures}

The WIE study used a contraceptive calendar similar to that used in the Ghana Demographic and Health Survey (GDHS) to record retrospective information of women regarding their use of contraceptives, discontinuation, reasons for switching and as well as births, pregnancies and terminations. For this paper, data for women who reported in the contraceptive calendar to have had given birth between 13 to 31 months prior to the interview were included for analysis. Postpartum period in this study refers to 12 months period after birth. Contraceptive methods were broadly categorized into no method, traditional methods and modern methods. Traditional methods include withdrawal and rhythm. Methods considered modern include sterilization, intrauterine device (IUD), implants, injectables, oral contraceptive pills (OCP), condom, emergency contraceptive (EC) pill and lactational amenorrhea method (LAM).

Based on the review of other studies on postpartum contraceptive use in sub-Saharan Africa $[4,6,11,12]$, a number of predictors were selected. Measurement for the selected predictors of postpartum modern contraceptive uptake is as follows: age of woman (16-24 years, 25-34 years and 35 years and above); marital status (never in union, currently in union, and formerly in union); educational level (no formal education, completed primary, completed middle/junior high school, completed secondary and tertiary/higher education); religion (Pentecostal, Catholic, Anglican/Methodist/presbyterian, other Christians, Moslem and no religion/other); parity (one live birth, two live births and three live births/more); received family planning (FP) counselling during antenatal care (ANC) (yes and no); ANC provider (nurse and physician); attended postnatal care (PNC) after birth (yes and no) and received FP counselling during PNC (yes and no). Having received ANC was dropped from the analysis because of collinearity.

\section{Analysis}

The prevalence of postpartum contraceptive use among women was estimated at one, three, six and 12 months following birth. A binary logistic regression model was also fitted to examine the predictors of postpartum 
modern contraceptive use. The binary logistic model was employed to examine associations with use of a modern method in the 12-month postpartum period: used a modern method in one or more months in the postpartum period versus never used a modern method in the postpartum period. Explanatory variables for the regression with $p$-values less than $5 \%$ were considered statistically significant for the analysis and discussed.

\section{Results}

\section{Background characteristics of women}

Table 1 shows that majority (55\%) of the women are within the age band $25-34$ years and more than $79 \%$ reported being in a union with a partner at the time of the interview. Except for some (14\%), most women had a form of formal education with over a third reporting to have completed secondary education or higher. Further, majority of the women are from the Akan (34\%) and Ga/Dangme (33\%) ethnic groups and a higher proportion also fall in the poorer $(20 \%)$ and average $(39 \%)$ wealth scale. Two-third $(71 \%)$ of postpartum women had reported having two or more live births. 
Table 1

Socio-demographic characteristics of women who delivered between 13-31 months before the survey Variable $(n=624)$

Frequency [\%]

Age of woman

$16-24$

$135[21.5]$

25-34

344 [55.1]

$35+$

145 [23.4]

Marital status

Never in union

98 [15.7]

Currently in union

494 [79.3]

Formerly in union

31 [5.0]

Educational level

No formal education

89 [14.3]

Completed primary

91 [14.6]

Completed middle/junior high school

230 [36.9]

Completed secondary

146 [23.4]

Higher

67 [10.8]

Religion

Catholic

18 [2.9]

Anglican/Methodist/Presbyterian

75 [12.0]

Pentecostal

340 [54.5]

Other Christian

126 [20.2]

Moslem

56 [9.0]

other/no religion

9 [1.4]

Ethnicity

Akan

211 [33.8]

Ewe

119 [19.1]

Ga/Dangme

204 [32.7]

Other Ghanaian

79 [12.7]

Non Ghanaian

11 [1.7]

Wealth

Poorest

59 [9.5] 


\begin{tabular}{|ll|}
\hline Variable $(\mathbf{n = 6 2 4 )}$ & Frequency [\%] \\
\hline Poorer & $125[20.0]$ \\
\hline Middle & $241[38.6]$ \\
\hline Richer & $156[25.0]$ \\
\hline Richest & $43[6.9]$ \\
\hline Parity & \\
\hline One & $183[29.4]$ \\
\hline Two & $207[33.3]$ \\
\hline Three and more & $232[37.3]$ \\
\hline
\end{tabular}

\section{Maternal health services women received and source of services}

Table 2 shows the services women received before and after birth, as well as providers of the services. Ninetynine percent of women had reported to have received at least one ANC visit before their last birth and of these, about $85 \%$ received ANC services for at least four times. Eighty percent of women had obtained their recent ANC service from a public hospital/clinic and the providers (96\%) were mostly nurses/midwifes. Only a few (4\%) had received their recent ANC service from a physician. Slightly over a three-quarters $(77 \%)$ of the women had ever received FP counselling during ANC services. Apart from a few (3\%) women who delivered at home, majority $(94 \%)$ had delivered in either a public $(78 \%)$ or private $(15 \%)$ hospital/clinic. Unlike ANC $(99 \%)$, a relatively lesser percentage of women $(93 \%)$ had attended PNC after delivery. Further, majority (87\%) of the women had received FP counselling during PNC. 
Table 2

Maternal health services women received for the last pregnancy and source of services

\begin{tabular}{|c|c|}
\hline Variable & Frequency [\%] \\
\hline Received any antenatal care ${ }^{\psi}$ & $\mathrm{n}=(587)$ \\
\hline Yes & $580[98.8]$ \\
\hline No & 7 [1.2] \\
\hline \multicolumn{2}{|l|}{ Place of antenatal care } \\
\hline Home & $2[0.3]$ \\
\hline Government hospital/clinic & $461[79.5]$ \\
\hline Health post/CHPS/mobile clinic & $4[0.7]$ \\
\hline Private hospital/clinic & $100[17.2]$ \\
\hline Other private facilities (e.g. maternity home) & $12[2.1]$ \\
\hline Others & $1[0.2]$ \\
\hline \multicolumn{2}{|l|}{ Antenatal care provider } \\
\hline Doctor/gynaecologist & $21[3.6]$ \\
\hline Nurse or midwife & $556[95.9]$ \\
\hline Community health nurse/officer & $2[0.3]$ \\
\hline Traditional birth attendant (TBA) and others & $1[0.2]$ \\
\hline \multicolumn{2}{|l|}{ Frequency of antenatal care } \\
\hline One-three times & $43[7.4]$ \\
\hline Four times and above & $494[85.2]$ \\
\hline Don't know & $43[7.4]$ \\
\hline \multicolumn{2}{|l|}{ Received FP counseling during antenatal care } \\
\hline Yes & $449[77.4]$ \\
\hline No & $131[22.6]$ \\
\hline \multicolumn{2}{|l|}{ Place of delivery } \\
\hline Home & $19[3.2]$ \\
\hline Government hospital/clinic & $460[78.4]$ \\
\hline $\begin{array}{l}\text { Health post/community-based health planning and } \\
\text { services/mobile clinic }\end{array}$ & $2[0.3]$ \\
\hline Private hospital/clinic & 90 [15.3] \\
\hline Other private facilities (e.g. maternity home) & 9 [1.5] \\
\hline
\end{tabular}




\begin{tabular}{|ll|}
\hline Variable & Frequency [\%] \\
\hline Others & $7[1.2]$ \\
\hline Attended postnatal care after birth ${ }^{\psi}$ & $\mathrm{n}=(587)$ \\
\hline Yes & $548[93.4]$ \\
\hline No & $39[6.6]$ \\
\hline $\begin{array}{l}\text { Received family planning counseling during postnatal } \\
\text { care }\end{array}$ \\
\hline Yes & $477[87.0]$ \\
\hline No & $71[13.0]$ \\
\hline$\Psi=37$ women had missing information on both antenatal and postnatal care \\
\hline
\end{tabular}

\section{Contraceptive methods women used at months one, three and twelve after birth}

Table 3 shows the postpartum contraceptive methods women used at months one, three, six and 12 after birth. About $40 \%$ of postpartum women never used any contraceptive method during 12 months after birth. Of the women $(152+223=375)$ who had used a traditional or modern contraceptive method during the 12 months postpartum period, $59 \%$ had used a modern method with $15 \%$ of the methods being long-acting (specifically, implants (10\%), IUD (3\%) and sterilization (2\%)) and $44 \%$ being short-acting (specifically, injectables (16\%), male condom ( $11 \%)$, LAM $(8 \%)$, OCP $(5 \%)$, EC (3\%), and other ( $0.3 \%)$. Twenty-nine percent of women used a method in the immediate one month after birth. Of these methods users ( $81+97=178), 54 \%$ used a modern method with $14 \%$ of the methods being long-acting and $40 \%$ being short-acting contraceptives. Again, of the modern method users (97 women) in month one post-birth, 23\% were using LAM. Results further show that the uptake of contraceptives in general increased among all women during the 12 months postpartum period from $29 \%$ in the immediate one month to $60 \%$ in the 12 th month following birth (Figure 1).

\section{[Insert Figure 1 around here]}


Table 3

Postpartum contraceptive methods used at months one, three, six and twelve post-birth

\begin{tabular}{|lllll|}
\hline Methods (n=624) & Month 1 & Month $\mathbf{3}$ & Month 6 & Month 12 \\
\cline { 2 - 5 } & Frequency [\%] & Frequency [\%] & Frequency [\%] & Frequency [\%] \\
\hline No method & $446[71.5]$ & $389[62.3]$ & $311[49.8]$ & $249[39.9]$ \\
\hline Traditional & $81[13.0]$ & $103[16.5]$ & $133[21.3]$ & $15224.4]$ \\
\hline Rhythm & $55[8.8]$ & $70[11.2]$ & $93[14.9]$ & $107[17.1]$ \\
\hline Withdrawal & $24[3.8]$ & $28[4.5]$ & $35[5.6]$ & $40[6.4]$ \\
\hline Other traditional & $2[0.3]$ & $5[0.8]$ & $5[0.8]$ & $5[0.8]$ \\
\hline Modern & $97[15.5]$ & $132[21.2]$ & $180[28.8]$ & $223[35.7]$ \\
\hline Female Sterilization & $7[1.1]$ & $7[1.1]$ & $7[1.1]$ & $7[1.1]$ \\
\hline Intrauterine device & $4[0.6]$ & $9[1.4]$ & $10[1.6]$ & $11[1.8]$ \\
\hline Implants & $15[2.4]$ & $24[3.8]$ & $29[4.6]$ & $39[6.3]$ \\
\hline Injectables & $19[3.0]$ & $24[3.8]$ & $41[6.6]$ & $62[9.9]$ \\
\hline Pills & $10[1.6]$ & $13[2.1]$ & $18[2.9]$ & $20[3.2]$ \\
\hline Male condom & $16[2.6]$ & $23[3.7]$ & $36[5.8]$ & $42[6.7]$ \\
\hline Emergency contraceptive & $4[0.6]$ & $5[0.8]$ & $8[1.3]$ & $111.8]$ \\
\hline Lactational amenorrhea method & $22[3.5]$ & $27[4.3]$ & $30[4.8]$ & $30[4.8]$ \\
\hline Other modern & & & $1[0.2]$ & $1[0.2]$ \\
\hline
\end{tabular}

\section{Factors associated with the uptake of modern contraceptives in postpartum period}

Table 4 shows results for both adjusted and unadjusted logistic model fitted for the predictors of modern contraception uptake in the 12 months period post-birth. For the unadjusted model, postpartum modern contraceptive use is significantly associated with parity, educational level and postnatal counseling. For instance, postpartum women with record of only one live birth were less likely to use a modern method compared with those with three or more live births $(\mathrm{OR}=0.6, \mathrm{p}<0.05)$. Also, women who reported that they had not received FP counseling during the postpartum period had lower odds of using a modern method relative to their counterparts who had received FP counseling $(\mathrm{OR}=0.6, \mathrm{p}<0.05)$. Postpartum women with tertiary education or higher were 2.3 times as likely to use modern contraceptive compared with those with no formal education. Even after adjusting for other factors, women with tertiary education or higher were 2.9 times as likely to use a modern method compared with those with no formal education. However, after accounting for other factors, postnatal FP counseling did not significantly predict postpartum modern contraceptive use. The adjusted model further shows that women formerly in a union with a partner were less likely to use a modern contraceptive during the postpartum period compared with those currently in a union $(\mathrm{OR}=0.3, \mathrm{p}<0.05)$. Like the unadjusted, results for the adjusted model shows that postpartum women with just one live birth are less likely to use a modern contraceptive during the postpartum period. Further, results from the adjusted model show that women with 
higher age had lower odds of using modern methods in the postpartum period. Religion of woman, whether woman received family planning counselling during ANC or not, the type of ANC provider and whether woman attended PNC after birth were not significantly predicting postpartum modern contraceptive uptake. Having received $\mathrm{ANC}$ or otherwise was dropped from the regression analysis because of collinearity. 
Table 4

Predictors of modern contraceptive use in postpartum period

\begin{tabular}{|c|c|c|c|c|c|c|c|c|}
\hline \multirow{2}{*}{$\begin{array}{l}\text { Variable } \\
\text { Age of woman }\end{array}$} & \multirow[t]{2}{*}{ UOR } & \multirow[t]{2}{*}{$\begin{array}{l}\mathrm{P} \text { - } \\
\text { value }\end{array}$} & \multicolumn{2}{|c|}{$95 \% \mathrm{Cl}$} & \multirow[t]{2}{*}{ AOR } & \multirow[t]{2}{*}{$\begin{array}{l}\mathrm{P} \text { - } \\
\text { value }\end{array}$} & \multicolumn{2}{|c|}{$95 \% \mathrm{Cl}$} \\
\hline & & & & & & & & \\
\hline \multicolumn{9}{|l|}{ 16-24 (Ref) } \\
\hline $25-34$ & 0.92 & 0.68 & 0.61 & 1.38 & 0.64 & 0.08 & 0.39 & 1.06 \\
\hline $35+$ & 0.84 & 0.49 & 0.52 & 1.37 & 0.41 & 0.01 & 0.21 & 0.78 \\
\hline \multicolumn{9}{|l|}{ Marital status } \\
\hline \multicolumn{9}{|l|}{ Currently in union (Ref) } \\
\hline Never in union & 0.65 & 0.08 & 0.41 & 1.05 & 0.70 & 0.20 & 0.40 & 1.21 \\
\hline Formerly in union & 0.47 & 0.09 & 0.20 & 1.12 & 0.27 & 0.02 & 0.09 & 0.84 \\
\hline \multicolumn{9}{|l|}{ Educational level } \\
\hline \multicolumn{9}{|l|}{ No formal education (Ref) } \\
\hline Completed primary & 1.97 & 0.04 & 1.04 & 3.70 & 1.98 & 0.05 & 0.99 & 3.96 \\
\hline Completed middle/junior high school & 1.68 & 0.06 & 0.98 & 2.90 & 1.76 & 0.06 & 0.97 & 3.18 \\
\hline Completed secondary & 1.36 & 0.30 & 0.76 & 2.45 & 1.60 & 0.16 & 0.83 & 3.08 \\
\hline Higher & 2.33 & 0.01 & 1.18 & 4.57 & 2.87 & 0.01 & 1.37 & 6.04 \\
\hline \multicolumn{9}{|l|}{ Religion } \\
\hline \multicolumn{9}{|l|}{ Pentecostal (Ref) } \\
\hline Catholic & 1.26 & 0.64 & 0.48 & 3.34 & 1.24 & 0.68 & 0.44 & 3.47 \\
\hline Anglican/Methodist/Presbyterian & 1.56 & 0.09 & 0.94 & 2.59 & 1.51 & 0.14 & 0.87 & 2.60 \\
\hline Other Christian & 1.26 & 0.28 & 0.83 & 1.93 & 1.57 & 0.06 & 0.98 & 2.52 \\
\hline Moslem & 0.73 & 0.32 & 0.39 & 1.37 & 0.66 & 0.23 & 0.33 & 1.31 \\
\hline other/no religion & 2.48 & 0.18 & 0.65 & 9.41 & 2.33 & 0.27 & 0.53 & 10.29 \\
\hline \multicolumn{9}{|l|}{ Parity } \\
\hline One & 0.61 & 0.02 & 0.40 & 0.92 & 0.43 & 0.00 & 0.25 & 0.73 \\
\hline Two & 0.89 & 0.54 & 0.60 & 1.30 & 0.64 & 0.05 & 0.41 & 1.01 \\
\hline \multicolumn{9}{|l|}{ Three (ref) } \\
\hline \multicolumn{9}{|l|}{$\begin{array}{l}\text { Received family planning counseling } \\
\text { during antenatal care }\end{array}$} \\
\hline \multicolumn{9}{|l|}{ Yes (Ref) } \\
\hline Otherwise $\psi$ & 0.66 & 0.05 & 0.44 & 1.00 & 0.65 & 0.06 & 0.42 & 1.02 \\
\hline
\end{tabular}




\begin{tabular}{|c|c|c|c|c|c|c|c|c|}
\hline Variable & UOR & $\begin{array}{l}\text { P- } \\
\text { value }\end{array}$ & \multicolumn{2}{|c|}{$95 \% \mathrm{Cl}$} & AOR & $\begin{array}{l}\text { P- } \\
\text { value }\end{array}$ & \multicolumn{2}{|c|}{$95 \% \mathrm{Cl}$} \\
\hline \multicolumn{9}{|c|}{ Attended postnatal care after birth } \\
\hline \multicolumn{9}{|l|}{ Yes (Ref) } \\
\hline No & 0.60 & 0.17 & 0.28 & 1.25 & 0.63 & 0.35 & 0.23 & 1.68 \\
\hline \multicolumn{9}{|c|}{$\begin{array}{l}\text { Received family planning counseling } \\
\text { during postnatal care }\end{array}$} \\
\hline \multicolumn{9}{|l|}{ Yes (Ref) } \\
\hline Otherwise ${ }^{\psi \psi}$ & 0.58 & 0.02 & 0.37 & 0.93 & 0.75 & 0.34 & 0.41 & 1.36 \\
\hline \multicolumn{9}{|c|}{ Adjusted odd ratios: Observations $=585, \operatorname{LR}$ Chi2 $(18)=43.04$, Prob $>$ Chi2 $=0.00$} \\
\hline \multicolumn{9}{|c|}{ NB: Having received antenatal care or otherwise was dropped from the model because of collinearity. } \\
\hline \multicolumn{9}{|c|}{$\psi=$ The 7 women who reported had not received antenatal care are included } \\
\hline
\end{tabular}

\section{Discussion}

The study found that two in five postpartum women were not using any form of contraceptive during the one-year postpartum period, and were at risk of unintended pregnancy and likely to be lopped-off from the health benefits associated with postpartum contraception uptake. Moreover, among the women who used any method during the 12 months postpartum period, about 40 percent had used a traditional method. Traditional methods are often associated with high failure rates and thus, traditional method users are also at risk of unintended pregnancy though less than non-users of any method. Less than a third of women initiated the use of contraceptives in the immediate one month following birth. Studies show that about $52 \%$ of women often resume sex five to six weeks following birth and $90 \%$ would have had resumed sexual activity by the third month post-birth [17-19]. With this, some of the remaining two-third of women who had not used any method in the first month after birth might get pregnant. Our findings further show that only a few of the women who used a modern method in month one postbirth had used a long-acting contraceptive. Though, the fertility intentions of women were not ascertained in this study, the use of a long-acting methods generally enable women to effectively achieve best health outcomes in postpartum period through long pregnancy intervals [20].

On postpartum method mix, it is observed that rhythm (17\%) was predominantly used by postpartum women and followed by injectables (10\%). The use of rhythm/calendar method is largely based on one's knowledge of her menstrual cycle, especially the last menstruation. As such, women's use of rhythm is an indication that their menses had probably returned. Biologically, ovulation precedes menstruation and most of the women who reported using rhythm in the first month post-birth could potentially be fertile even before the method was used. The use of injectables by nearly a third (28\%) of modern method users is not surprising as this is consistent with a recent study conducted in the urban settings of Ghana. Coomson and Manu studied postpartum women who visited health facilities in Tema, an urban city in Ghana and indicated that close to $30 \%$ of women who reported using modern methods had used injectables [11]. In fact, the health facility survey, a component of the WIE study 
showed that most urban-poor women who covertly used contraceptives preferred injectables. Similar to findings of Coomson and Manu, less than a tenth of postpartum method users had used LAM. Seven women had opted for sterilization. It is most likely that these women had achieved their fertility intentions as further analysis (not reported here) showed that they all had three or more live births and are in their mid-thirties or above.

Regarding the predictors of postpartum modern contraception, results indicate that women with higher parity and higher educational level are more inclined to have used a modern method during the postpartum period. Women with higher education are expected to have better insights of the various contraceptive methods and would opt for more effective methods. Analysis of demographic and health survey data from 43 developing countries including Ghana showed that higher education positively influence uptake of postpartum family planning methods [21], corroborating our findings. Additionally, most women with higher parity are likely to have achieved or probably surpassed their fertility intentions and would, therefore, use modern methods that are effective for preventing unintended pregnancies. Findings also suggests that postpartum women currently in a union with a partner are inclined to use modern contraceptive relative to those formerly in union. Women currently in union are more likely to be sexually active and therefore exposed to the risk of pregnancy than women who were formerly in union. The use of maternal health services was not significantly influencing postpartum modern contraceptive uptake. However, the direction of the odd ratios seemingly suggests a positive influence on the use of modern contraceptives post-birth.

\section{Conclusion}

In conclusion, findings indicate that about $40 \%$ of postpartum women never used any contraceptive method in the one-year period following birth and even of the women who used a method, about $40 \%$ had used a traditional method. Moreover, a much smaller proportion (29\%) of women started using a method in the immediate onemonth post-birth. The methods women predominantly used in the 12 months postpartum period were rhythm and injectables. Results further indicate that postpartum modern contraceptive use is positively associated with higher education, having more live births and being currently in a union. The outcomes of the study suggest that most postpartum women in low-income urban settings are at risk of unintended pregnancy and likely to be lopped-off from the health benefits associated with optimal birth spacing.

Given that ANC and PNC visits are not significantly related to the use of modern contraceptive indicate that either the content or the process of such counselling are weak and require improvements. Such counselling may overlook the importance of postpartum contraception for maternal and child health, number of contraceptive methods available and their relative advantages and disadvantages or the counselling may have been brief. Therefore, improving the quality of counselling and the manner in which this is delivered during ANC and PNC visits require improvements. Also, community outreach by health providers/promoters or similar models should be promoted in low-income population settings to educate postpartum women on modern contraceptive use. Women who plan to use traditional methods should be provided with information on consistent and correct use of these methods. In particular, women who plan to use the rhythm method should be correctly informed of the fertile days in the cycle.

\section{Abbreviations}


ANC: Antenatal Care; EC: Emergency Contraceptive; FP: Family Planning; GDHS: Ghana Demographic and Health Survey; GSS: Ghana Statistical Service; IUD: Intrauterine Device; LAM: Lactational Amenorrhea Method; LMICs: Low- and Middle-Income Countries; mCPR: modern Contraceptive Prevalence Rate; OCP: Oral Contraceptive pill; PNC: Postnatal Care; PPC: Postpartum Contraceptives; WHO: World Health Organisation; WIE: Willows Impact Evaluation.

\section{Declarations}

\section{Ethical approval and consent to participate}

Ethical approvals were obtained from Ghana Health Service Ethical Review Committee (GHS-ERC: 005/08/2017), University of Ghana Ethics Committee for the Humanities (ECH 020/17-18) and the Institutional Review Board (IRB) of Harvard T.H. Chan School of Public Health (IRB 17-1107) before the study. All methods were performed in accordance with the relevant guidelines and regulations. Written informed consent was obtained from all respondents before participation in the study. No parental/guardian consent was required since data were collected from women aged 16 to 44 years. In Ghana, persons under the age of 16 years are considered minors.

\section{Consent for publication}

Not applicable.

\section{Availability of data and materials}

The datasets generated and/or analysed during the current study are not publicly available due to restrictions [Harvard T.H. Chan School of Public Health and Regional Institute for Population Studies do not permit data publicity before publication] but are available from the corresponding author on reasonable request.

\section{Competing interest}

The authors declare that there is no competing interest.

\section{Funding}

The study was funded under a grant to Harvard University by an Anonymous Donor.

\section{Authors' contributions}

CA substantially contributed to the conception of the study, methods, analysis and drafted the manuscript. EGH contributed to the conception of the study, methods, analysis and reviewed the manuscript for substantial intellectual content. POA contributed to the methods and reviewed the manuscript for important intellectual content. AOD, TT and MWA contributed to revising the manuscript for important intellectual content. IS and $A A B$ contributed to the methods, interpretation of the data and reviewed the manuscript as lead investigators of the study. All authors read and approved the final manuscript.

\section{Acknowledgments}

We acknowledge the administrative support from the Regional Institute for Population Studies, University of Ghana and Department of Global Health and Population, Harvard T.H. Chan School of Public Health. We also 
acknowledge the contributions of all field workers.

\section{References}

1 Cleland J, Bernstein S, Ezeh A, Faundes A, Glasier A, Innis J. Family planning: the unfinished agenda. The lancet. 2006; 368(9549):1810-27.

2 WHO. Postpartum family planning: essential for ensuring health of women and their babies. 2018. Retrieved from https://www.who.int/reproductivehealth/topics/family_planning/world-contraception-day-

2018/en/\#: :text=Pregnancies\%20in\%20the\%20postpartum\%20period,of\%20women\%20and\%20their\%20babies. Accessed on January 15, 2021.

3 Ross JA, Winfrey WL. Contraceptive use, intention to use and unmet need during the extended postpartum period. International family planning perspectives. 2001: 20-7.

4 Borda M, Winfrey W. Postpartum fertility and contraception: an analysis of findings from 17 countries. Baltimore: Jhpiego. 2010.

5 Dev R, Kohler P, Feder M, Unger JA, Woods NF, Drake AL. A systematic review and meta-analysis of postpartum contraceptive use among women in low-and middle-income countries. Reproductive health. 2019;16(1):1-7.

6 Eliason SK, Bockarie AS, Eliason C. Postpartum fertility behaviours and contraceptive use among women in rural Ghana. Contraception and reproductive medicine. 2018;3(1):1-2.

7 Stover J, Ross J. How increased contraceptive use has reduced maternal mortality. Maternal and child health journal. 2010;14(5):687-95.

8 WHO. Report of a WHO Technical Consultation on Birth Spacing. 2007. Retrieved from https://apps.who.int/iris/bitstream/handle/10665/69855/WHO_RHR_07.1_eng.pdf?sequenc e=1\&ua=1

9 Rutstein SO. Effects of preceding birth intervals on neonatal, infant and under-five years mortality and nutritional status in developing countries: evidence from the demographic and health surveys. International Journal of Gynecology \& Obstetrics. 2005;89:S7-24.

10 Bongaarts J. A framework for analyzing the proximate determinants of fertility. Population and development review. 1978:105-32.

11 Coomson Jl, Manu A. Determinants of modern contraceptive use among postpartum women in two health facilities in urban Ghana: a cross-sectional study. Contraception and reproductive medicine. 2019;4(1):1-1.

12 Morhe ES, Ankobea F, Asubonteng GO, Opoku B, Turpin CA, Dalton VK. Postpartum contraceptive choices among women attending a well-baby clinic in Ghana. International Journal of Gynecology \& Obstetrics. 2017;138(2):219-24.

13 Atiglo DY, Biney AA. Postpartum and post-abortion contraceptive use among unmarried young women in Ghana. Journal of Biosocial Science. 2020:1-2. 
14 Kwasi P. Effects of rapid urbanisation on urban livelihoods in Ghana. 2014.

https://www.ghanaweb.com/GhanaHomePage/features/Effects-Of-Rapid-Urbanisation-On-Urban-Livelihoods-InGhana-339152. Accessed on Jan 15. 2021.

15 Hove M, Ngwerume ET, Muchemwa C. The urban crisis in Sub-Saharan Africa: a threat to human security and sustainable development. Stability. (2013); 2(1): 7.

16 Dimagi Inc. CommCare (version 2.40.1) [Mobile application software]. 2018.

17 Leeman LM, Rogers RG. Sex after childbirth: postpartum sexual function. Obstetrics \& Gynecology. 2012;119(3):647-55.

18 Glazener CM. Sexual function after childbirth: women's experiences, persistent morbidity and lack of professional recognition. BJOG: An International Journal of Obstetrics \& Gynaecology. 1997;104(3):330-5.

19 Rogers RG, Borders N, Leeman LM, Albers LL. Does spontaneous genital tract trauma impact postpartum sexual function?. Journal of midwifery \& women's health. 2009;54(2):98-103.

20 Harrison MS, Goldenberg RL. Immediate postpartum use of long-acting reversible contraceptives in low-and middle-income countries. Maternal health, neonatology and perinatology. 2017 Dec;3(1):1-9.

21 Winfrey W, Rakesh K. Use of family planning in the postpartum period. 2014.

\section{Figures}

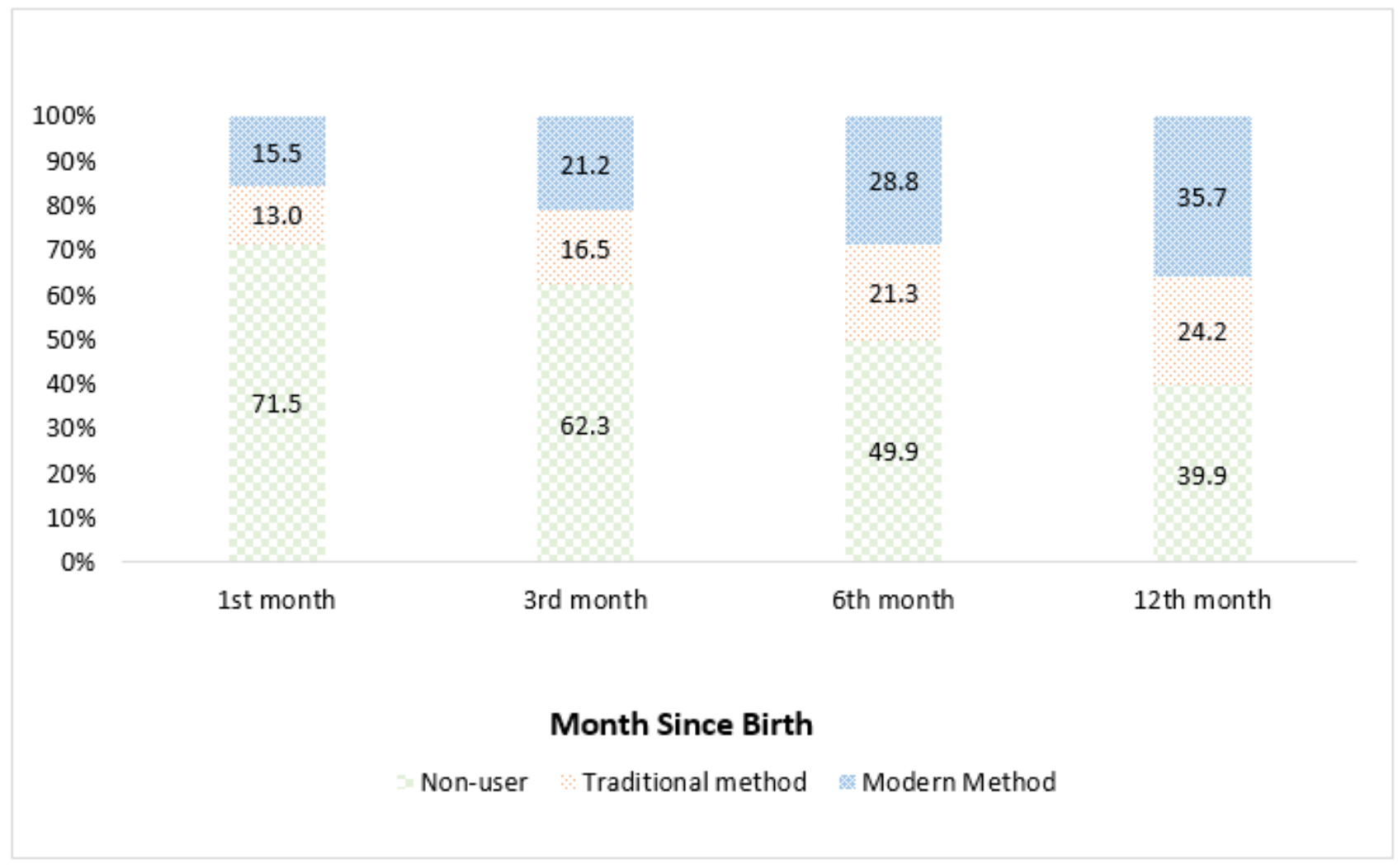




\section{Figure 1}

Percent of women using no method, a traditional method or a modern method, by month since birth 